LUNDBY, Knut. Mediatization of Communication. Berlim/ Boston: De Gruyter Muoton, 2014.

\title{
RESENHA DO LIVRO MEDIATIZATION OF COMMUNICATION
}

\author{
Nicolás Llano Linares ${ }^{1}$
}

Se faz alguns anos as perguntas recorrentes nas pesquisas sobre os meios de comunicação eram formuladas a partir da preocupação dos pesquisadores com a influência que o consumo do conteúdo midiático exercia tanto na vida das pessoas quanto nas diferentes instituições políticas, religiosas, sociais e culturais, o novo milênio trouxe uma complexidade excepcional à configuração histórica do panorama midiático. Hoje, a mídia além de ser entendida e estudada como espaço de transmissão, ator opinativo e agente informativo, transformou-se em elemento constitutivo da organização social. Desnorteado pela rapidez das mudanças nos sistemas, papéis e interações tecno-comunicativas, o campo da comunicação, já não só ocupado em entender a influência e papel dos meios massivos nas diferentes dimensões da vida cotidiana, continua na busca de compreender e analisar as implicações das contínuas mudanças das tecnologias comunicativas e dos processos de mediação sócio-comunicativos.

Para todo aquele que tenha aprofundado no estudo da teoria da midiatização nos últimos dez anos, Knut Lundby, professor de estudos mediáticos e diretor do departamento de Comunicação e Mídia da Universidade de Oslo, deve ser uma figura minimamente conhecida. Lundby, quem em 2009 organizou um dos primeiros livros que reuniu as diferentes abordagens sobre a teoria da midiatização em língua inglesa (Mediatization: Concept, Changes, Consequences. New York: Peter Lang, 2009), tem-se constituído em uma figura importante na formulação do debate contemporâneo sobre a teoria da midiatização no continente europeu.

Desde a publicação desse primeiro volume de artigos reunidos ao redor das primeiras formulações sistemáticas sobre a midiatização - definida pelo autor como o conceito que busca caracterizar "as mudanças nas práticas, culturas e instituições" nas

\footnotetext{
${ }^{1}$ Mestre em Ciências da Comunicação pela ECA-USP, membro do Grupo de Estudos Semióticos em Comunicação, Cultura e Consumo. Doutorando em Ciências da Comunicação pela Universidade de São Paulo. E-mail: nllano@usp.br
} 
diferentes sociedades (LUNDBY, 2014: 26) -, sua formulação teórica tem atravessado por várias fases (ainda em debate e desenvolvimento) a partir dessas formulações iniciais: a exploração da convergência e diferenciação terminológica (COULDRY, 2008; 2012; MATTOS, JANOTTI, JACKS, 2012); a classificação de correntes teóricas (COULDRY, 2012; COULDRY, HEPP, 2013; HEPP, 2013); e a conceptualização dos ambientes midiáticos (HORST, HERR-STEPHENSON, ROBINSON, 2010; MADIANOU, MILLER, 2013).

Não é apressurado dizer que Mediatization of Communication apresenta-se como um marco importante tanto qualitativa quanto quantitativamente na literatura acadêmica sobre a midiatização, pois revela de maneira engenhosa e rigorosa às virtudes, fraquezas e formulações futuras de uma das teorias mais discutidas e controvertidas dentro do campo da comunicação e dos estudos midiáticos nos últimos anos. Organizado em oito blocos temáticos, os artigos reunidos no livro ilustram o amadurecimento tanto das fundações teóricas quanto das análises individuais que vêm ampliando cada vez mais o leque de objetos que pretendem ser entendidos a partir dos modelos e conceitos da teoria da midiatização.

Além de importantes contribuições sobre temas tratados de forma recorrente sob a lente da midiatização como a religião (Mia Lövhein) e a política (Jesper Strömbäck, Frank Esser; Øyvin Ilhen e Josef Pallas), destacamos as contribuições feitas sobre objetos não estudados tradicionalmente a partir desta teoria, especialmente os artigos que exploram objetos ligados aos campos da cultura e das artes, como o trabalho de Johan Förnas, quem apresenta um modelo evolutivo que inclui diferentes fases do processo de midiatização da cultura popular na Europa desde o século XVI; a análise das mudanças midiáticas e sua relação com as transformações nas práticas e organizações esportivas de Kirsten Frandsen, e também, a inventiva formulação aplicada da midiatização às mudanças climáticas expostas por Risto Kunelius.

Como argumenta Nick Couldry no seu artigo incluído neste livro, o debate acerca a midiatização tem sido 'tímido' em aproximar sua conceptualização em constante processo com outras bases teóricas que permitam entender e avaliar a reconfiguração das "dinâmicas e dimensões da ação no espaço social" em uma época marcada pela saturação dos fluxos midiáticos em todas as dimensões das nossas vidas (COULDRY, 2014: 381). Nesse sentido, vários artigos aqui contidos cumprem com o 
papel de avançar no aprofundamento e refinamento teórico da midiatização a partir das diferentes correntes identificadas (institucional; social-construtivista; material ou tecnológica), ampliando às possibilidades oferecidas por outras teorias próprias das ciências sociais.

Desse modo, acreditamos que os trabalhos de André Janson; Andreas Hepp, Uwe Hasebrink; Stig Hjarvard; Friedrich Krotzl Mirca Madianou e o próprio Nick Couldry são contribuições significativas para o avanço de teoria que continuamente tem reclamado da falta de ancoragem e operacionalização de seus fundamentos teóricos com outros conceitos, campos e disciplinas; trabalhos que também buscam suprir a falta de abordagens metodologias de muitos estudos sobre a midiatização que procurem nas pesquisas empíricas os dados suportem seus argumentos e validem suas hipóteses.

Como capitulo final Sonia Livingstone e Peter Lunt, (Mediatization: an emerging paradigm for media and communication research) assinam, na minha opinião, o ponto mais destacado do volume; nele os autores articulam uma síntese crítica dos últimos quinze anos de desenvolvimento teórico sobre a midiatização, provocando diversas reflexões pertinentes sobre a validade do conceito em relação a outras contribuições e formulações do campo da comunicação e os estudos midiáticos; assim como discutem a crescente tendência de pensar que tudo pode e está sendo midiatizado.

O maior logro deste novo livro que suma-se à crescente literatura sobre a teoria da midiatização é que em sua totalidade a obra evidencia tanto os avanços e correntes atuais da teoria, quanto suas lacunas e limitações. Além dos vários aspectos positivos da coleção, dois tópicos ainda revelam tópicos pouco abordados na produção acadêmica em torno à midiatização: a falta de pesquisas que adoptem abordagens empíricas que forneçam dados mensuráveis como suporte dos seus conceitos e argumentos (importante sublinhar uma das exceções da regra no trabalho apresentado de Mirca Madianou); e segundo, embora tenha sido uma grata surpresa encontrar um artigo de Eliseo Verón no livro (Mediatization Theory: a semioanthropological perspective), a falta de variedade continental dos autores presentes na coleção atesta a grande carência do conhecimento e projeção internacional das contribuições Latino-Americana sobre a teoria da midiatização. 
A multiplicidade de objetos analisados nos mais de 30 artigos que compõem o livro, e as diferentes interpretações analíticas dos conceitos teóricos formulados na última década, fazem de Mediatization of Communication um marco importante no entendimento histórico e evolutivo das diferentes fases, preocupações e avanços da formulação de uma teoria que busca em termos gerais entender o papel da mídia e da comunicação nas transformações da nossa realidade social. Se a mídia, as tecnologias da comunicação e os processos de comunicação midiática estão cada vez mais presentes e são progressivamente mais determinantes na construção da realidade social, este volume demonstra que a busca da formulação de uma teoria que idealmente combine uma perspectiva não mídia-cêntrica, que explore novas possibilidades metodológicas e que valide seus argumentos com dados empíricos, tem como futuro promissório transformar-se em uma importante contribuição teórica do campo da comunicação e os estudos midiáticos às ciências sociais.

\section{REFERÊNCIAS BIBLIOGRÁFICAS}

LUNDBY, Knut. Mediatization of Communication. Berlim/ Boston: De Gruyter Muoton, 2014.

Artigo submetido: 09/06/2014

Artigo aprovado: 10/07/2014 